\title{
Compressive strength of young Taiwania (Taiwania cryptomerioides) trees grown with different thinning and pruning treatments
}

Received: March 2, 2005 / Accepted: September 30, 2005 / Published online: March 2, 2006

\begin{abstract}
Taiwania (Taiwania cryptomerioides Hay) is an important timber species in Taiwan. Growth in generally improved trees under intense silvicultural practice is so rapid that rotations or the practice of thinning trees may be as short as 20-30 years. Thus, the wood properties of young plantation trees need to be characterized to effectively use this resource. The effects of different thinning and pruning methods on the compressive strength parallel to grain of young Taiwania trees were explored. Average compressive strengths with various thinning treatments revealed the trend of no thinning $>$ medium thinning $>$ heavy thinning and in the pruning treatments showed the trend of medium pruning $>$ no pruning $>$ heavy pruning. However, most results showed no statistically significant differences among thinning and pruning treatments.
\end{abstract}

Key words Taiwania Compressive strength · Thinning · Pruning

\section{Introduction}

Strength properties, for example, bending and compressive strengths, important to the effectiveness of utilization of wood as a building and construction material, are known to vary within and between trees, and with wood species, tree age, silvicultural practices, and for other reasons. ${ }^{1}$ In general, tree growth can be directly controlled by plantation techniques. These include thinning and pruning, which are two important practices for commercial plantation wood.

\section{C.-J. Lin}

Division of Forest Utilization, Taiwan Forestry Research Institute, Taipei 100, Taiwan

S.-Y. Wang $(\varangle) \cdot$ T.-H. Yang $\cdot$ M.-J. Tsai

School of Forestry and Resource Conservation, College of

Agriculture, National Taiwan University, 1 Roosevelt Rd, Sec 4,

Taipei 106, Taiwan

Tel. +88-622-363-1736; Fax +88-622-363-1736

e-mail: sywang@ntu.edu.tw
From a series of investigations on the wood quality of Taiwania (Taiwania cryptomerioides Hay) trees grown under different thinning and pruning treatments, density, ring traits, bending properties, and knot traits have been reported previously. ${ }^{2-5}$ However, there have been few investigations concerning the effects of thinning and pruning practices on the compressive strength properties as evaluated by the compressive test. ${ }^{6-9}$ Therefore, the purpose of the study was to investigate the effects of thinning and pruning treatments on the compressive strength of Taiwania trees. The results may provide information for silvicultural practices and structural utilization of wood.

\section{Materials and methods}

The trees used in this study were located on a site at an elevation of $1600 \mathrm{~m}$ in compartment no. 12, Liukuei Experimental Forest, Taiwan Forestry Research Institute (TFRI), Kaohsiung, southwestern Taiwan. The mean annual temperature, relative humidity, and precipitation from 1986 to 1993 were $18.6^{\circ} \mathrm{C}, 81 \%$, and $2280 \mathrm{~mm}$, respectively. In addition, from 1994 to 2001, the same measurements were $17.1^{\circ} \mathrm{C}, 86 \%$, and $3706 \mathrm{~mm}$, respectively. About $88 \%$ of the rainfall in given year falls during the period from April to September.

The site was about $2.0 \mathrm{ha}$, and it was divided into 27 plots of 0.04 ha including buffer zones. The study plantation was planted at a rate of 1750 trees/ha in 1980. Thinning and pruning treatments were implemented in 1990 . The three levels of thinning used were heavy thinning $\left(27.60 \mathrm{~m}^{2} / \mathrm{ha}\right)$, medium thinning $\left(32.52 \mathrm{~m}^{2} / \mathrm{ha}\right)$ and no thinning $\left(41.95 \mathrm{~m}^{2} /\right.$ ha). Stocks were harvested from the original state $\left(41.95 \mathrm{~m}^{2} /\right.$ ha) to produce the medium $\left(32.52 \mathrm{~m}^{2} / \mathrm{ha}\right)$ and heavy $\left(27.60 \mathrm{~m}^{2} / \mathrm{ha}\right)$ thinning treatments.

The stock was calculated using Eq. 1:

$S=\mathrm{BA} / A$

where $S\left(\mathrm{~m}^{2} / \mathrm{ha}\right)$ is the stock, BA $\left(\mathrm{m}^{2}\right)$ is the total basal area of all trees at a tree height of $1.3 \mathrm{~m}$ [diameter at breast 
Table 1. Structure of Taiwania stands with different thinning treatments

\begin{tabular}{|c|c|c|c|c|c|c|c|}
\hline Treatment & Phase & $\begin{array}{l}\text { Age } \\
\text { (years) }\end{array}$ & $\begin{array}{l}\text { Density } \\
\text { (trees/ha) }\end{array}$ & $\begin{array}{l}\text { Mean } \\
\text { DBH }(\mathrm{cm})\end{array}$ & $\begin{array}{l}\text { Mean } \\
\text { height (m) }\end{array}$ & $\begin{array}{l}\text { Basal area } \\
\left(\mathrm{m}^{2} / \mathrm{ha}\right)\end{array}$ & $\begin{array}{l}\text { Volume } \\
\left(\mathrm{m}^{3} / \mathrm{ha}\right)\end{array}$ \\
\hline \multirow{3}{*}{$\begin{array}{l}\text { Heavy thinning } \\
\left(27.60 \mathrm{~m}^{2} / \mathrm{ha}\right)\end{array}$} & Before thinning & 11 & 1750 & 17.13 & 9.85 & 42.42 & 197.38 \\
\hline & After thinning & 11 & 929 & 19.69 & 10.41 & 27.60 & 131.65 \\
\hline & After 9 more years & 20 & 811 & 28.03 & 15.21 & 50.04 & 342.53 \\
\hline \multirow{3}{*}{$\begin{array}{l}\text { Medium thinning } \\
\left(32.52 \mathrm{~m}^{2} / \mathrm{ha}\right)\end{array}$} & Before thinning & 11 & 1689 & 17.39 & 9.93 & 42.17 & 197.00 \\
\hline & After thinning & 11 & 1135 & 19.14 & 10.32 & 32.52 & 154.45 \\
\hline & After 9 more years & 20 & 1097 & 26.56 & 15.80 & 60.78 & 432.14 \\
\hline \multirow{2}{*}{$\begin{array}{l}\text { No thinning } \\
\qquad\left(41.95 \mathrm{~m}^{2} / \mathrm{ha}\right)\end{array}$} & - & 11 & 1801 & 16.89 & 9.81 & 41.95 & 195.47 \\
\hline & - & 20 & 1528 & 23.53 & 15.50 & 66.44 & 463.45 \\
\hline
\end{tabular}

$\mathrm{DBH}$, diameter at breast height

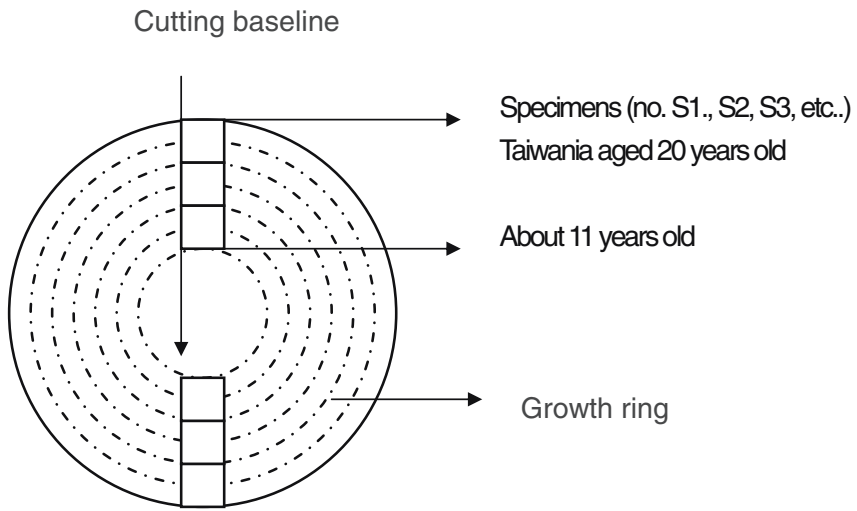

Fig. 1. Notation of specimen logs cut from one side to the other. S1, S2, and S3 specimens, etc. are the numbers of the small clear specimens

height (DBH) position], and $A$ (ha) is the area of the experimental site.

The three pruning levels were heavy pruning $(4.5 \mathrm{~m}$ of tree height), medium pruning ( $3.6 \mathrm{~m}$ of tree height), and no pruning and also shown as the $45.5 \%$ (heavy) and $36.4 \%$ (medium) of the tree height. The heavy and medium pruning treatments were represented by trees that were pruned to within $4.5 \mathrm{~m}$ and $3.6 \mathrm{~m}$ of the trunk height, respectively.

Three levels of thinning were combined with three levels of pruning treatment. Therefore, nine silvicultural practices (three thinning $\times$ three pruning treatments) were used in this study. The same thinning and pruning treatment plot was repeated three times. Therefore, in total, 27 sample plots were designed. The diameter and height of each tree from the 27 small plots were measured. Average DBH and tree heights are shown in Table 1.

One cross-sectional disc ( $10 \mathrm{~cm}$ thick) was cut from each sample tree at the position of its DBH on 13 or 14 February 2001 , when the trees were about 20 years old. A diametrical strip (passing through the pith) was sawn from each disc in the same direction, and then small clear specimens $(30 \mathrm{~mm}$ long $\times 15 \mathrm{~mm}$ wide $\times 15 \mathrm{~mm}$ thick) were cut from the strip, as shown in Fig. 1. In this study, at least six small, clear specimens from each disc were used to explore the compressive properties of juvenile wood grown with different thinning and pruning treatments. Thus, a total of more than 162 specimens were measured (three replicates $\times$ more than six specimens $\times$ three thinning treatments $\times$ three pruning
Table 2. The juvenile wood properties of young Taiwania in this study

\begin{tabular}{ll}
\hline Property & Average value \\
\hline Ring width (mm) & $5.21(0.92)$ \\
Latewood percentage (\%) & $13.89(4.25)$ \\
Ring density $\left(\mathrm{kg} / \mathrm{m}^{3}\right)$ & $390(30)$ \\
Tracheid length (mm) & $3.17(0.20)$ \\
Microfibril angle (degree) & $18.05(1.43)$ \\
Bending modulus of elasticity $(\mathrm{MPa})$ & $3643.9(872.8)$ \\
Bending modulus of rupture $(\mathrm{MPa})$ & $49.6(6.8)$ \\
Compressive strength $(\mathrm{MPa})$ & $25.3(0.8)$ \\
Heartwood ratio $(\%)$ & $45.3(5.7)$ \\
\hline
\end{tabular}

Data taken from earlier reports. ${ }^{8,11,13}$ Values in parentheses represent the standard deviation

treatments). The cambium ages of the sample specimens were from 11 to 20 years old (from different silvicultural regimes for tests).

The small clear specimens were also conditioned in a controlled-environment room at $20^{\circ} \mathrm{C}$ and $65 \%$ relative humidity so that the specimens had a moisture content of $12 \%$. The compressive strength parallel-to-grain test was conducted in accordance with the CNS $453^{10}$ (Method of test for compression of wood), using a universal-type testing machine (Hung-Ta, Taipei, Taiwan). All deformation curves were obtained from the compressive test, and then the ultimate compressive strengths parallel to grain $\left(\sigma_{\mathrm{c}}\right)$ were calculated from ultimate load.

\section{Results and discussion}

Table 2 provides some basic statistics concerning average values in ring width, ring density, latewood percentage, tracheid length, microfibril angle, modulus of elasticity in bending, modulus of rupture in bending, and heartwood ratio. These values were devised from different studies of the same sample Taiwania tree. ${ }^{2,5,11}$ The mean values of the wood properties in this study were similar to the results of $\mathrm{Chou}^{1}$ for this species in four age groups.

Chiu et al. ${ }^{12}$ indicated that the position of demarcation between juvenile and mature wood occurred at an approximate distance of $10.8-13.2 \mathrm{~cm}$ from the pith that was about 18-20 years of cambium age in Taiwania. Therefore, in this experiment, specimens contained a high proportion 
Table 3. Comparisons of density, compressive strength, and the modulus of elasticity of small clear specimens obtained from different thinning and pruning regimes

\begin{tabular}{|c|c|c|c|c|c|c|}
\hline \multirow[t]{2}{*}{ Treatment level } & \multicolumn{2}{|c|}{ Ring width (mm) } & \multicolumn{2}{|c|}{ Density $\left(\mathrm{kg} / \mathrm{m}^{3}\right)$} & \multicolumn{2}{|c|}{ Compressive strength ( $\mathrm{MPa})$} \\
\hline & Thinning & Pruning & Thinning & Pruning & Thinning & Pruning \\
\hline Heavy & $5.8 \mathrm{a}(0.48)$ & $5.3 \mathrm{ab}(0.41)$ & 364.6a (17.4) & 369.3a (19.6) & $24.6(2.3)$ & $24.3(3.3)$ \\
\hline Medium & $5.2 \mathrm{~b}(0.42)$ & $4.7 \mathrm{a}(0.37)$ & 391.0b (27.9) & $399.5 b(32.1)$ & $25.2(2.3)$ & $26.3(4.2)$ \\
\hline None & $4.7 \mathrm{~b}(0.38)$ & $5.6 \mathrm{~b}(0.45)$ & 397.7b (30.1) & $384.5 \mathrm{ab}(27.4)$ & $26.2(4.7)$ & 25.3 \\
\hline
\end{tabular}

Means within a given column with the same letter are not significantly different $(P \geqq 0.05)$ as determined by Duncan's multiple-range test. Values in parentheses represent the standard deviation

of juvenile wood, and may not yet be considered mature wood. Thus, wood quality may have been influenced by the characteristics of juvenile wood. It is known that juvenile wood is inferior to that of mature wood in most wood utilizations. Wang and $\mathrm{Chiu}^{13}$ reported that juvenile wood has substantially less mechanical strength than mature wood of the same specific gravity.

Differences in average ring width (RW), wood density $(\rho)$, and compressive strength $\left(\sigma_{\mathrm{c}}\right)$ among specimens cut from trees subjected to different thinning and pruning levels were analyzed using analysis of variance (ANOVA) and Duncan's new multiple-range test. The results are shown in Table 3. The effects of thinning by pruning interaction and other interactions on the RW, $\rho$, and $\sigma_{\mathrm{c}}$ were not significant, and were not analyzed further.

As shown in Table 3, the RW in the thinning treatments showed the following trend: heavy thinning $>$ medium thinning > no thinning. However, The RW in the pruning regimes was in the following decreasing order: no pruning $>$ heavy pruning $>$ medium pruning. According to the results of statistical analysis shown in Table 3 , significant difference $(P<0.05)$ exists for the RW between heavy thinning and medium/no thinning treatments, and between medium pruning and no pruning treatments. This indicates that heavy thinning produced wider annual rings than medium or no thinning. Moreover, pruning treatments cause narrower annual rings than does no pruning. These results were similar to those in the report of Wang et al. ${ }^{2}$

The average density of specimens from the thinning treatments showed the trend of no thinning $>$ medium thinning $>$ heavy thinning. In addition, the average density of specimens from the pruning treatments showed the trend of medium pruning $>$ no pruning $>$ heavy pruning. Therefore, higher average densities of Taiwania were obtained those trees subjected to no thinning and medium pruning treatments.

These results are similar to those previously reported by Wang et al. ${ }^{4,5}$ who indicated that this tendency may be attributed to the fact that trees grown in relatively wider spaces have wider ring widths and lower densities. This showed that with wider annual ring widths, there was lower wood density in the rings. On the contrary, with narrower ring widths, the wood density in the rings was higher.

In addition, some studies have reported that thinning causes a slight decrease in wood density for Pinus radiata and Pseudotsuga menziesii. ${ }^{14-16}$ However, others have indicated that thinning had no effect or only minor effects on the wood densities of Pinus pinaster, Pinus radiata, and Pinus taeda. ${ }^{17-20}$ Similar results have been reported on the earlywood and latewood density of Douglas fir. ${ }^{21}$ From these results, it can be seen that heavy thinning reduces the average values of wood density within the annual rings.

Zobel and van Buijtenen ${ }^{22}$ also indicated that wood density increases in some species with pruning, because pruning apparently causes early cessation of juvenile wood formation and promotes latewood formation. They also stated that pruning has no effect on the specific gravity of Eucalyptus grandis. The wood quality is affected by the changes in growth pattern caused by removal of parts of the live crown (i.e., a different effect of pruning). One of the main concerns is that pruning will reduce growth rate. Because of the decrease of the live crown, lower photosynthesis is expected and tree growth rate may also be decreased. When tree growth rate is decreased, narrower ring width is accompanied by higher density. Therefore, it is usually recommended that pruning to the desired tree height results in the removal of no more than one third to one half of the live crown.

As shown in Table 3, the average values of $\sigma_{\mathrm{c}}$ with thinning treatments showed the trend of no thinning $>$ medium thinning $>$ heavy thinning. This tendency indicates that heavy thinning produced smaller $\sigma_{\mathrm{c}}$ values than medium and no thinning treatments. Variations of $\sigma_{\mathrm{c}}$ with pruning treatments showed the trend of medium pruning $>$ no pruning $>$ heavy pruning. This indicates that medium pruning produced larger $\sigma_{\mathrm{c}}$ values than heavy and no pruning treatments. These tendencies are similar to those previously reported by Wang et al., ${ }^{4,5}$ who indicated that better average bending properties of Taiwania wood occurred in the no thinning and medium pruning treatments. However, differences between the thinning and pruning treatments were not statistically significant.

In this experiment, the average compressive strength was 24.3-26.3 MPa. This is similar to the results of Lin et al., ${ }^{23}$ who indicated that the compressive strength was 24.131.3 MPa for Taiwania as determined using a Fractometer tool. Chou ${ }^{1}$ indicated that compressive strengths of young Taiwania plantation trees of different ages and tree heights, and within-tree variations were 16.1-28.5 MPa. 


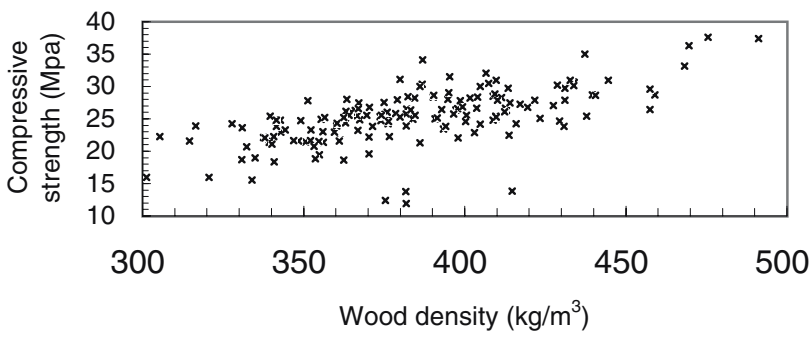

Fig. 2. Relationship between wood density and compressive strength of the specimens

In general, the density is known to be closely correlated with $\sigma_{\mathrm{c}}$. In this experiment, the density increased with the increase in compressive strength, with a positive correlation that existed between density and strength (Fig. 2). The relationship can be expressed as: compressive strength $=0.07$ density $-3.44\left(R^{2}=0.39, F=32.7\right.$, significant at the 0.01 level).

In the current study, all tests were done on clear wood specimens. Therefore, the effect of the pruning treatments on the density or compressive strength does not consider the effect of knots. In fact, it is well known that knotty wood is much weaker and has a higher density. Wang et al. ${ }^{5}$ indicated that the average air-dried density of lumber was higher than that of the specimens, because the specimens were clear and the lumber contained high-density knots. Pruning treatments help improve lumber quality, while thinning treatments help increase volume growth. In addition, the effect of crown size (growth capacity or photosynthesis) after pruning on the $\mathrm{DBH}$ and wood quality is important. Wang et al. $^{2}$ reported that the DBH was significantly increased by thinning, but was decreased by pruning. They also indicated that thinning reduces the average ring density, but pruning had little effect on wood density.

A cause for the variation in results (within and between trees, and within and between rings) may have been that juvenile wood has various degrees of impact on the compressive strength. In this study, the sampled trees (20 years old) contained a high proportion of low-quality juvenile wood. Juvenile wood can be characterized by short tracheid length, thin cell walls in the rings, large microfibril angles, and other factors in the tracheids. ${ }^{8,24}$ These results are similar to those reported earlier by Wang and $\mathrm{Chiu}^{13}$ for Japanese cedar and Kaya and Smith ${ }^{25}$ for red pine.

\section{Conclusions}

The properties of Taiwania, an important building and construction material, are known to vary with different silvicultural treatments. Wood qualities of young trees need to be understood to successfully use this resource. The effects of different thinning and pruning methods on the compressive properties of young Taiwania trees were investigated. The compressive strength after thinning and pruning treatments showed the trend of no thinning $>$ medium thinning $>$ heavy thinning, and medium pruning $>$ no pruning $>$ heavy pruning. However, differences between the thinning and pruning treatments were not statistically significant. Results showed that the thinning and pruning treatments had no effect on compressive strength. Correlation between density and compressive strength of Taiwania specimens could be represented by positive linear regression formulas.

Acknowledgments The authors thank the Taiwan Forest Research Institute and the National Science Council of Taiwan for financial support through grant NSC 93-2313-b-002-038.

\section{References}

1. Chou C (1998) Effects of age on strength properties of Taiwania plantation wood. Taiwan J For Sci 13:119-125

2. Wang SY, Chiu CM, Lin CJ (2003) Application of the drilling resistance method for annual ring characteristics evaluation of Taiwania (Taiwania cryptomerioides Hay.) trees grown in different thinning and pruning treatments. J Wood Sci 49:116-124

3. Wang SY, Lin CJ, Chiu CM (2003) Effects of thinning and pruning on knots and lumber recovery of Taiwania (Taiwania cryptomerioides Hay.) planted in the Lu-Kuei area. J Wood Sci 49:444-449

4. Wang SY, Lin CJ, Chiu CM (2005) Evaluation of wood quality of Taiwania trees grown with different thinning and pruning treatments using the ultrasonic-wave method. Wood Fiber Sci 37: 192-200

5. Wang SY, Lin CJ, Chiu CM, Chen JH, Yung TH (2005) Dynamic modulus of elasticity and bending properties of Taiwania young trees grown with different thinning and pruning treatments. J Wood Sci 51:1-6

6. Watanabe H, Tsutsumi J, Matsumoto T, Ohta S (1964) Studies on juvenile wood. II. On distribution of specific compressive strength and specific modulus of elasticity in stem of sugi-tree Cryptomeria japonica D. Don. Mokuzai Gakkaishi 10:125-130

7. Bendtsen BA, Senft J (1986) Mechanical and anatomical properties in individual growth rings of plantation-grown eastern cottonwood and loblolly pine. Wood Fiber Sci 18:23-38

8. Bao FC, Jiang ZH, Jiang XM, Lu XX, Luo XQ, Zhang SY (2001) Differences in wood properties between juvenile wood and mature wood in 10 species grown in China. Wood Sci Technol 35: $363-375$

9. Kasal B (2003) Semi-destructive method for in-situ evaluation of compressive strength of wood structural members. Forest Prod J 53:55-58

10. MEA (1981) Method of test for compression of wood. Bureau of standards, metrology and inspection, Ministry of Economic Affairs (MEA), CNS453

11. Chiu CM, Lin CJ, Wang SY (2005) Tracheid length and microfibril angle of young taiwania grown under different thinning and pruning treatments. Wood Fiber Sci 37:437-444

12. Chiu CM, Wang SY, Lin CJ, Yang TH, Jane MC (2006) Application of the fractometer for crushing strength: juvenile-mature wood demarcation in Taiwania (Taiwania cryptomerioids). J Wood Sci 52:9-14

13. Wang SY, Chiu CM (1993) Wood properties of Japanese cedar originated by seed and vegetative reproduction in Taiwan VI. Compression and bending properties. Mokuzai Gakkaishi 39: $1128-1139$

14. Cown DJ (1974) Comparison of the effects of two thinning regimes on some wood properties of radiata pine. NZ J For Sci 4:540-551

15. Erickson HD, Harrison AT (1974) Douglas-fir wood quality studies. V. Effects of age and stimulated growth on wood density and anatomy. Wood Sci Technol 8:207-226

16. Barbour RJ, Foyle DC, Chauret G, Cook JA, Karsh MB, Ran S (1994) Breast height relative density and radial growth in mature Jack pine (Pinus banksiana) for 38 years after thinning. Can J Forest Res 24:2439-2447 
17. Nicholls JWP (1971) The effects of environmental factors on wood characteristics. 2. The effect of thinning and fertilizer treatment on the wood of Pinus pinaster. Silvae Genet 20:67-73

18. Cown DJ (1973) Effects of severe thinning and pruning treatments on the intrinsic wood properties of young radiata pine. NZ J For Sci 3:379-389

19. Trylor FW, Barton JD (1982) Growth ring characteristics, specific gravity, and fiber length of rapidly grown loblolly pine. Wood Fiber Sci 14:204-210

20. Moschler WW, Dougal EF, McRae DD (1989) Density and growth ring characteristics of Pinus taeda L. following thinning. Wood Fiber Sci 21:313-319

21. Megraw RA, Nearn WT (1972) Detailed DBH density profiles of several trees from Douglas-fir fertilizer/thinning plots. Proceedings of Symposium on the Effect of Growth Acceleration on the Properties of Wood. Madison, WI, USDA Forest Service

22. Zobel BJ, van Buijtenen JP (1989) Wood variation its cause and control. Springer, Berlin Heidelberg New York, pp 218-248

23. Lin CJ, Wang SY, Chiu CM (2004) Assessment of compressive strength in Taiwania using the Fractometer. Taiwan Forest Prod Ind 23:23-31

24. Zobel BJ, Sprague JR (1998) Juvenile wood in forest trees. Springer, Berlin Heideberg New York, pp 26-38

25. Kaya F, Smith L (1993) Variation in compression strength and some related properties of a red pine. Wood Sci Technol 27: 229-239 